\title{
The Role of Emotional Intelligence on Workplace Bullying and Individuals' Work Performance
}

\author{
W A M S U Gunawardena \\ Nilakshi W K Galahitiyawa
}

\begin{abstract}
Even though emotional intelligence has been proposed to mitigate the adverse effects of stressful situations such as workplace bullying, previous studies have yet failed to explain as to how emotional intelligence affects the relationship between workplace bullying and individual work performance. Accordingly, this paper aims to explain the effect of emotional intelligence on the relationship between workplace bullying and work performance. A survey was conducted among 230 managerial level employees and their supervisors in the fast-moving consumer goods industry. Emotional intelligence and workplace bulling were measured through a self-administered questionnaire while their performance was assessed by supervisors. Data was analysed using structural equation modelling (SEM) with AMOS software. The empirical data supported the negative relationship between workplace bullying and an individual's work performance. Study also finds that person-related bullying was the most influential form of bullying that affects an individual's work performance. Furthermore, study revealed that the negative relationship between workplace bullying and work performance is weaker for those with high EI and stronger for those with low EI. Theoretical contribution of this paper is the extension of our understanding of workplace bullying on individual's work performance by bringing emotional intelligence as a moderator. The paper recommends to managers to use emotional intelligence as a strategy to mitigate the adverse effects of workplace bullying on individuals' work performance.
\end{abstract}

Keywords: Emotional Intelligence, Individual's Work Performance, Person-related bullying, Workplace Bullying, Work-related bullying.

Ms. W A M S U Gunawardena is a Lecturer, Imperial Institute of Higher Education. E-mail: su.gunawardena@gmail.com

Dr. Nilakshi W K Galahitiyawa is Senior Lecturer, University of Sri Jayewardenepura. E-mail: nilakshi.g@gmail.com 


\section{Sri Lankan Journal of Management}

Vol. 21, No. 1, January - June, 2016

\section{Introduction}

Therecent yearshave witnessed aswift turn towardsglobalization and competitiveness among organizations. Organisations are faced with ever changing pressures, such as global competition, consumer demand, technological change, changing labour expectations, environmental awareness, and economic recession (French \& Bell, 2009; Halal, 2007; Limerick \& Cunnington, 2003). Evidence of corporate reaction to the uncertainty produced by these pressures may be seen in the growth of contemporary managerial buzzwords such asflexibility, market orientation, flattening structures, managerial excellence, productivity, quality, re-training, participation and creativity (Hilmer \& Donaldson, 2006; Pascale, 2008). The intensity of this competition increases the emphasis on proficiency with which individuals perform the core substantive or technical tasks central to their job. Every organization wants to stay ahead of the competition and it searches for ways to augment its performance and to achieve the maximum utilization of human resources (Individual's Work Performance). To reach this goal, organisations use a variety of ways and means, and one mechanism appears to be workplace bullying, because in this highly competitive setting, managers may perceive that they have a mandate to use whatever technique necessary to deploy their human resources (Cascio, 2005). This is because severe competition among organisations also increases managerial stress (Charlesworth, 2006). These pressures tend to "lower the threshold at which managers, particularly those operating at the limits of their skills, and competencies, are adopting bullying behaviours even if involuntarily" (McCarthy, 1996, p. 48). Organisations appear to have developed a culture whereby the achievement of organisational goals justifies the reasons for using such mechanisms (Charlesworth, 2006). Workplace bullying refers to "situations where a person repeatedly and over a period of time is exposed to negative acts (i.e. constant abuse, offensive remarks or teasing, ridicule or social exclusion) on the part of co-workers, supervisors, or subordinates" (Einarsen, 2009, 2000; Mikkelsen \& Einarsen, 2002, p. 397). Margaret (2007) defines workplace bullying as the repeated mistreatment of one employee who is targeted by one or more employees with a malicious mix of humiliation, intimidation and sabotage of performance. It includes being ridiculed in the presence of other employees, being lied about to others, the feeling of always being on guard, not being able to focus on the assigned work tasks and loss of self-confidence.

Employee performance is critical for determining and maintaining organizational efficiency and effectiveness, but constant exposure to bullying at work is associated 


\section{The Role of Emotional Intelligence on Workplace Bullying and Individuals' Work Performance}

with impaired job performance (Bowling \& Beehr, 2006). Indeed, a growing research interest has been shown regarding workplace bullying and its consequences, and one meta-analysis also showed that higher levels of workplace harassment (a label frequently used to describe workplace bullying) were related to lower levels of job performance, (Bowling \& Beehr, 2006).

It has also been argued that workplace bullying is not just a cognitive process but also an emotional one (Cartwright, 2008), suggesting that the behaviour is more a function of emotional regulation than of rational or cognitive processes. According to the argument of Samnani et al., (2013), the impact of workplace bullying on a target's performance varies according to the way he or she perceives the bullying event. Samnani et al., (2013) speculate that a target's performance is likely to increase or decrease depending on whether the target interprets a perpetrator's motive or intent as positive or negative, perceives bullying as work-driven vs. non-work driven, or perceives bullying as person-driven or context-driven. When a target does not recognize the negative intent of the bullying event or the perpetrator, and makes "positive" attributions about the bullying behaviour, it will not have a negative effect on his or her performance, and if a target perceives a negative intent, it will have a negative effect on his or her performance (Samnani et al., 2013).

Workplace bullying has been identified as a major type of work- related stress (Aquino, 2008, p.61). According to the individualized transactional coping theory developed by Lazarus (1999), when people encounter stressful life events, they try to change the adverse effects of these events on their well-being by using a number of coping strategies (Akgun, 2004, p.49). According to the study done by Matthews and Ziender (2005), individuals' emotional intelligence skills influence their choices of coping strategies used to deal with the stressful situations they face. Another study showed that individuals with high emotional intelligence cope effectively with the stress generated by workplace bullying and harassment and those with low emotional intelligence use more avoidance-oriented coping strategies such as consuming alcohol, smoking and becoming addicted to junk food (Furnham et al., 2010; Eskay, 2011). Mayer and Sullivan (2007) believe that one's emotional intelligence skills are related to high levels of coping. This emotional organisation process can help to decrease the frequency and intensity of stressors, even in enduring stressful situations. Riley and Schutte (2003) considered emotional intelligence to be a coping mechanism that leads to useful self-regulation put in place in order to overcome the stress generated by negative workplace activities such as harassment, bullying 


\section{Sri Lankan Journal of Management}

Vol. 21, No. 1, January - June, 2016

and verbal abuse. According to the study done by Chan (2006), individuals with enhanced emotional intelligence are less vulnerable to work-related stress generated by work place bullying and harassment.

Based on the previous studies, it is clear that although many researchers argue that workplace bullying leads to impaired job performance, it is evident that the impact of the bullying incident may vary according to the level of emotional intelligence that an individual possesses. Even though the impact and importance of emotional intelligence has been proposed to mitigate the adverse effects of stressful situations such as workplace bullying, prior research has yet failed to provide a concrete answer to the problem of "How emotional intelligence affects the relationship between workplace bullying and individual work performance." This study is developed to identify the significant role played by emotional intelligence on the relationship between workplace bullying and work performance. Thus the purpose of this study is to examine the role played by emotional intelligence in mitigating the adverse effects of workplace bullying on an individual's work performance.

In order to theorize the aforementioned relationships of this study 'individualized transactional coping theory' and 'attribution theory' is applied. Individualized transactional coping theory developed by Lazarus (1999) declared that when people come across stressful life events, they try to mitigate the unfavorable effects of these events on their security by using a number of coping strategies (Akgun, 2004). The ability to interpret and regulate emotions in relation to negative situations should facilitate the effective management of energy and thought processes. (Lazarus, 1999) If individuals are able to understand their emotional reactions to demands, they are more likely to be able to adapt to the situation and cope with stress effectively.

Attribution theory is concerned with how individuals interpret events and how this relates to their thinking and behaviour. According to Heider (1958), reaction towards any situation varies according to the way an individual perceives the event, depending on whether the target interprets a perpetrator's motive or intent as positive or negative. Thus these two theories provided the premise for the establishment of the arguments and the relationships of the study.

The rest of the paper is structured as follows. It begins with an introduction, followed by an explanation of the findings of previous scholarly work on workplace bullying, an individual's work performance and emotional intelligence. The next section 
comprises of the conceptual framework for the research that is supported by the hypotheses. The latter section presents the methodology adopted to analyse the data and the discussion of findings. The theoretical and managerial implications, limitations and areas for further research are presented at the end of the paper.

\section{Literature Review}

\section{Workplace Bullying and its Consequences}

Workplace bullying is the persistent exposure to negative and aggressive behaviours, which may be psychological, verbal, or physical, and may be perpetrated by an individual or a group (Einarsen et al., 2011; O'Moore et al., 2008). Such negative behaviours are labelled as bullying when they "occur repeatedly and regularly (e.g. weekly) and over a period of time (e.g. about six months)" (Einarsen et al., 2011, p. 22). Bullying is primarily psychological and persistent, and on this basis it is distinguished from workplace violence, which is primarily physical and irregular.

The concept of bullying may be used in many situations, describing a variety of behaviours (Crawford, 1998). Bullying may even be used to describe a joking manner known as good-natured horseplay or refer to minor events of aggressive behaviour that tend to be easily accepted and tolerated (Munthe, 2009). However, in the scientific studies reviewed in this study, the concept refers to a rather specific phenomenon, where hostile and aggressive behaviours, be it physical or non-physical, are directed systematically at one or more colleagues or subordinates leading to a stigmatisation and victimization of the recipient (Leymann, 2006; BjoÈrkqvist et al., 2011). Bullying has been defined as all those repeated actions and practices that are directed at one or more workers, which are unwanted by the victim, and which may be done deliberately or unconsciously, but clearly cause humiliation, offence and distress, that may interfere with job performance and/or cause an unpleasant working environment (Einarsen \& Raknes, 1997). This definition emphasises the two main features of most definitions of bullying at work: repeated and enduring aggressive behaviours that are intended to be hostile and/or perceived as hostile by the recipient (Einarsen, 2009).

Work place bullying is dichotomous and categorised as person-related bullying and work-related bullying (Einersan, 2009). Person-related bullying behaviours comprise of public humiliation, ignoring, insulting, spreading rumours or gossip, 


\section{Sri Lankan Journal of Management}

Vol. 21, No. 1, January - June, 2016

intruding on privacy and yelling etc. (Beswick, Gore \& Palferman, 2006). Workrelated bullying behaviours consist of setting unachievable goals, impossible deadlines, unmanageable workloads, meaningless tasks or supplying unclear information, threat about security, etc. (Beswick, Gore, \& Palferman, 2006).

Bullying can have severe effects on individual targets and on the organisation. At the individual level, the results of bullying include lower self-esteem and more negative emotions such as anxiety, stress, fatigue, burnout and depression (Agervold \& Mikkelsen, 2004; Cassitto et al., 2004; Djurkovic et al., 2008; Hauge et al., 2010; Hoel et al., 2004; Lovell \& Lee, 2011; Lutgen \& Sandvik, 2008). Although strain and well-being are related, strain is the outcome of experiencing stresses and is focused on environmental factors whereas well-being captures individual traits, social cues, and cognitive processes (Warr, 2006). Bullying also negatively affects organisations: targets take more days off, report unclear expectations of task performance, have reduced job satisfaction, commitment to the organisation and work motivation and are more likely to leave the organisation than non-targets (Agervold \& Mikkelsen, 2004; Djurkovic et al., 2008; Harvey et al., 2007; Keashly \& Neuman, 2004). Performance represents a key outcome for the organisation, while organisational commitment is an important attitude in itself which also has implications for task performance, contextual performance and turnover (Sinclair et al., 2005).

\section{An Individual's Work Performance}

Individual work performance is an issue that has not only interested companies all over the world but also fueled a great deal of research in the fields of management, occupational health, and work and organisational psychology. Numerous studies on individual work performance have been conducted. However, different approaches to studying individual work performance circulate in today's literature (Koopmans, 2011). A widely endorsed definition of work performance is that of Campbell: "behaviours or actions that are relevant to the goals of the organization." Viswesvaran and Ones (2008, p.324) defined work performance as "scalable actions, behaviour and outcomes that employees engage in or bring about that are linked with and contribute to organizational goals." Borman and Motowidlo (2000) argue that the entire work performance domain could be encompassed by the comprehensive dimensions of task performance and contextual performance. They describe task performance as behaviours that directly or indirectly contribute to the organization's technical core, and contextual performance as behaviours that support the organizational, social, 
and psychological environment in which the technical core must function. Examples of contextual activities are volunteering, persisting, helping, cooperating, and following rules. Task activities usually vary with different jobs, whereas contextual activities are common to many or all jobs.

\section{The Role of Emotional Intelligence}

Salovey, Bedell, Detweiler and Mayer (2000) state that Emotional Intelligence (EI) is "a person's ability to adapt and cope in life depending on the integrated functioning of emotional and rational capacities (p. 506)." Emotional Intelligence is the ability to identify, assess and manage one's own emotions and the emotions of others. It is about recognizing how your own behavioural pattern is affected by different emotions, and recognizing the emotional states of others. Emotions are a complex state of feelings that result in physical and psychological changes that influence our behaviour. Considering the role of Emotional Intelligence, it can be seen to have significant benefits for individuals because Emotional Intelligence has consistently been linked with positive outcome measures, including life and work satisfaction, interpersonal functioning, healthy relationships, job performance, psychological well-being, physical health and psycho physiological measures of adaptive coping (Martins, Ramalho, \& Morin, 2010). From the perspective of the humanistic existential approach, everyone has the potential to grow and develop. Assessing one's emotional intelligence and presenting the findings affords one an opportunity to engage in self-exploration which may potentially lead to self-growth and self- actualisation and indirectly lead to improved job performance. According to Carl Rogers' theory of self-concept, people who are emotionally intelligent are able to process information logically, cognitively and efficiently, and on the basis of this, make informed decisions and manage themselves (Coetzee et al., 2006). EI has an impact on every aspect of one's life (private and professional) (Coetzee et al., 2006) and impacts on communication and interpersonal competencies as well as career decision-making processes and behaviours. EI has seen a resurgence of interest with the recent focus on positive psychology (Seligman \& Csikszentmihalyi, 2000), which emphasizes the fundamental role of personal resources, privileging interventions aimed at developing and boosting these resources and protective factors. Within the workplace, this approach suggests that EI may be an important predictor of work performance. 


\section{Sri Lankan Journal of Management}

Vol. 21, No. 1, January - June, 2016

Emotional Intelligence helps employees to successfully cope with occupational stress as well as with workplace bullying (Giorgi \& Majer, 2008). Particularly, managers with high EI report better health and well-being (Slaski \& Cartwright, 2002). Emotional Intelligence pertains to the ability to understand emotion and emotional knowledge as well as the ability to regulate emotions to promote educational and intellectual growth (Cooper \& Sawaf, 2010), and this may help employees to overcome the inner turmoil generated by workplace bullying acts.

\section{Individualized Transactional Coping Theory}

Transactional theories focus on the psychological processes that link an individual to the environment. These theories maintain that psychological stress arises when environmental demands faced by an individual are not matched by that individual's appraisal of the resources available to cope with those demands (Lazarus, 1999). Within the transactional perspective there are various models and approaches. One of the most widely adopted of all stress models is the model of Lazarus and Folkman (1984). This model maintains that psychological stress is the interaction between the environmental demands that threaten or challenge an individual and the individual's appraisal of the resources available to him/her to adapt to and cope with those demands. This model considers stress to be an iterative process involving appraisals of threat or challenge (primary appraisal), coping and then reappraisal. Demands consist of implicit or explicit pressures from the environment or situations that individuals are required to deal with (Lazarus, 1999). There are multiple demands within the working environment, all of which can become sources of psychological stress. However, not all demands invariably result in stress and some, such as deadlines, workloads and hours of work, can result in job satisfaction as well as stress (Cavanaugh et al., 2000). Processes of appraisal and coping mediate the relationship between a person, his/her environment and outcomes (Lazarus, 1999). Appraisal is the ongoing evaluation of the environment by an individual in terms of its significance for well-being (Lazarus \& Folkman, 1984).

Primary appraisal involves the process of evaluating a situation to determine whether it is perceived to be relevant and whether resources are available to deal with it. A situation can be appraised as threatening or challenging. A challenge appraisal concentrates on the anticipation of success and positive outcomes, confidence in one's ability and the resources available to cope with the demand. A threat appraisal focuses on the possible harm posed by the lack of resources available to allow for 
effective coping with the demand (Skinner \& Brewer, 2002). Appraisals are learned from previous experience and are influenced by individual difference variables, such as individual emotional resources and situational factors (Matthews et al., 2002).

Secondary appraisal involves an evaluation of the resources and coping options that might be useful for minimizing the stress of the threatening situation (Auerbach \& Gramling, 1998). Secondary appraisal is the choice of coping strategies available to deal with the demand, while coping involves implementing the choice. Coping may be defined as the "constantly changing cognitive and behavioural efforts to manage specific external and internal demands that are appraised as taxing or exceeding an individual's resources" (Lazarus \& Folkman, 1984, p. 110). Adaptive coping strategies include task-focused coping which attempts to manage the demand, and social support which involves drawing upon the resources of others (Auerbach \& Gramling, 1998; Folkman \& Moskowitz, 2004; Hagihara et al., 2003). Less adaptive strategies include denying and avoiding or psychologically distancing oneself from a demand (Anshel, 2001). Poorer levels of mental health are associated with avoidance coping than with task-focused coping or social support (Rick \& Guppy, 1994). Challenge appraisals are more likely to be associated with the use of task-focused coping than threat appraisals (Anshel, 2001). Social support is also used to reduce the stress associated with a situation that has been appraised as a challenge (Anshel, 2001). Avoidance is more likely if a situation is appraised as a threat rather than as a challenge (Lazarus, 1999).

\section{Attribution Theory}

Attribution theory began with the work of Heider (1958 cited in Baxter \& Blaithwaite, 2008; Hewstone, 1983). Heider's theories are grounded on the premise that people use attributions in order to make sense of the world and their surroundings to better control their environments and to create causal explanations (Baxter \& Blaithwaite, 2008; Stainton \& Rogers, 2011). This involves discriminating between the internal (one's inside) and external (one's surrounding) causes. This appears to be a protective action (Stainton \& Rogers, 2011). According to the theory, an individual will make attributions about a person based on his/her perception of the event. Also predictions will be made whether the event is stable or unstable (referring to the likelihood that it may happen again), and whether controllable or uncontrollable (to what extent it could be helped). Reaction towards any situation varies according to the way an individual perceives the event, depending on whether the target interprets a 


\section{Sri Lankan Journal of Management}

Vol. 21, No. 1, January - June, 2016

perpetrator's motive or intent as positive or negative. This was supported to a certain degree by the research conducted by Visconti, Secler and Kochendefer (2013), which was conducted on the attribution of child victimisation. They found differences in the attributions made (and thus whether the child sought support). This was dependent on the type of bullying which occurred. The attributions seemed to offer a protective measure. This theory is further explained by the research conducted by Samnani (2013), which was based on workplace bullying. Samnani (2013) found that the impact of workplace bullying varies according to the attributional process of the individual and that growth or deterioration of the individual's work performance due to workplace bullying depends on the way he or she perceives the intention of the bullying event as being positive or negative.

\section{Hypotheses and Conceptual Framework}

Throughout the literature review, related concepts of workplace bullying, an individual's work performance and emotional intelligence, which were the key variables identified in the context of the study, and based on these independent and dependent variables and the moderating variables, the hypotheses and the conceptual framework were developed.

\section{Workplace Bullying and Individuals' Work Performance}

Bullying has been defined as "repeated and persistent negative actions towards one or more individual(s), which involve a perceived power imbalance and create(s) a hostile work environment" (Salin, 2003, p. 1214). An individual's work performance refers to his/ her proficiency with which he or she performs activities which contribute to the organization's technical core. Workplace bullying has negative repercussions at all levels of the organization. It is well known that as a result of being bullied, employees can suffer from a wide range of emotional, physical and behavioural problems. Bullying creates a stressful working environment for all employees who are exposed to it. This is because as a way of dealing with their frustration, individuals who are bullied may go on to treat others in the same way (Hoel et al., 2003), thus, intensifying the hostile working environment. Importantly, the work of today's organizations are centered around teams, and since teams are composed of individuals who are linked together to achieve objectives, if one or more members of a team are suffering, the entire team may be weakened, both in terms of its interpersonal climate as well as its performance levels. In their research, Coyne 
et al., (2004) showed that teams in which bullying occurred were perceived to have lower levels of performance than those in which victimization had not occurred. Thus bullying reduces team cohesion and team performance levels, and, ultimately undermines the reputation and performance of the organization.

Thus it can be hypothesized that:

H1: There is a negative relationship between workplace bullying and workplace performance

\section{Person-related Bullying and Individuals' Work Performance}

Person-related bullying is defined as the repeated mistreatment of one employee who is targeted by one or more employees with a malicious mix of humiliation, intimidation and sabotage of performance (Margeret, 2007). Person-related bullying behaviours are public humiliation, ignoring, insulting, and spreading rumours or gossip, intruding on privacy, yelling etc. (Beswick, Gore \& Palferman, 2006). It causes a lack of focus on work tasks and a loss of self-confidence on the job (Yahaya et al., 2009). Person-related bullying is regarded as a form of stress capable of causing negative effects on workers' health, potentially leading to psychophysical symptoms, alterations of mood and personality, psychiatric disorders such as anxiety-depression disorder, chronic adjustment disorder and post-traumatic stress disorder which directly lead to impaired job performance (Yahaya et al.,2009). According to the study done by Brotheridge and Lee (2010), person-focused attacks such as public humiliation, undermining self-identity can have a severe impact on work performance. Moreover the anger and desire for revenge that belittlement generates leads to counterproductive work behaviours (Brotheridge \& Lee, 2010). Judith (2008) with her research study on workplace bullying, "Aggressive Behaviour and its effect on job satisfaction and productivity", showed how person-related bullying behaviour affects an individual's ability to perform his/her jobs, which in turn impacts the morale of an employee and finally the financial performance of the organization. Judith (2008) has found that the performance level and productivity level of employees who are frequently mistreated (bullied) are relatively lower than employees who were not victimized. The study of Miles et al., (2007) also found that person-related bullying is a strong contributor towards work performance and negative acts such as belittling comments and persistent criticism of work appear to inflict a great deal of harm on employees. The study of Miles et al., (2007) also found that person-related bullying is a strong contributor towards work performance and 
Sri Lankan Journal of Management

Vol. 21, No. 1, January - June, 2016

negative acts such as belittling comments and persistent criticism of work appear to inflict tremendous harm on employees.

Thus it can be hypothesized that:

H2: There is a negative relationship between person-related bullying and workperformance

\section{Work-related bullying and Individuals' Work Performance}

Some examples of work-related bullying behaviours are giving unachievable tasks, impossible deadlines, unmanageable workloads, meaningless tasks or supplying unclear information, and threats about security (Beswick, Gore, Palferman, 2006). In one meta-analysis, Bowling and Beehr (2006) found a significant positive effect of work-related harassment on counterproductive work behaviours and turnover intentions. Moreover, Ayoko et al., (2003) examined the role of workplace bullying and the associated emotional reactions of victims in influencing workplace counterproductive behaviours, and found that higher levels of bullying (as well as associated negative emotional reactions) were associated with higher levels of decreased/impaired job performance. Brotheridge and Lee (2010) mentioned in their study that bullying-induced emotions might have a negative impact on a target's job performance; furthermore, they stated that to the extent that employees (target) experience restlessness due to bullying, they are likely to have difficulty becoming fully engaged and effective in task performance (Brotheridge \& Lee 2010). Finn and Chattopadhyay (2000) stated that negative emotions generated by negative acts usually have a stronger psychological impact, and tend to produce emotion-focused coping, and thus targets may withdraw from work through denial, tardiness, and absenteeism as a form of avoidance coping (Weiss \& Cropanzano,2006). These behaviours may impede career success and have an adverse effect on organizational overall performance. Work-related bullying reduces employee effectiveness because the ensuing negative effect and physical symptoms hamper employees from performing optimally. Furthermore, targets may adopt avoidance strategies, such as absenteeism and turnover, to avoid being bullied which also might impede the growth of the organization.

Thus it can be hypothesized that:

$\mathrm{H}_{3}$ : There is a negative relationship between work-related bullying and work performance 
The Role of Emotional Intelligence on Workplace Bullying and Individuals' Work Performance

\section{Emotional Intelligence, Workplace Bullying and Individuals' Work Performance}

A considerable amount of research over the past decade has found that targets of bullying are likely to experience health problems such as anxiety and physical ailments (Mikkelsen \& Einarsen, 2001), diminished mental health (Hoel \& Cooper, 2000), and symptoms consistent with post-traumatic stress disorders (Leymann \& Gustafsson, 1996). Thus, rather than experiencing career success, workplace bullying can have a serious impact on one's performance and productivity levels. Bullying has been identified as a major type of work stress/job stress by numerous researchers. In interpersonal communication, emotionally intelligent persons are sensitive to emotions and feelings. Their response to a situation is not impulsive and hasty, but cautious and prudent. Thus, emotionally intelligent individuals make their emotions work for themselves by reflecting on and controlling actions to improve performance (Weisinger, 1998). Literature suggests that workplace bullying may trigger positive or negative emotions in the one who is bullied, contingent upon how the target evaluates the bullying behaviour (Brotheridge\& Lee, 2010). People with high levels of emotional intelligence (EI) seem to possess emotional skills that allow them to cope effectively with the challenges/stressful situations they face and thus promote their well-being. Considering the role of emotional intelligence it has significant benefits for individuals because emotional intelligence has consistently been linked with positive outcome measures, including life and work satisfaction, interpersonal functioning, healthy relationships, job performance, psychological well-being, physical health, and psycho physiological measures of adaptive coping (Martins, Ramalho, \& Morin, 2010, p.591). The utility of Emotional Intelligence in accounting for the coping strategies individuals choose to implement has been theoretically recognized, although research in this area is meager. Salovey, Bedell, Detweiler and Mayer (2000) stated that "A person's ability to adapt and cope in life depends on the integrated functioning of emotional and rational capacities (p. 506)." The researchers state explicitly that "Emotionally intelligent individuals should be able to recognize and pursue the most effective means of coping when they come across difficult situations at work" (Salovey et al., 2000, p. 512).

Those who are emotionally intelligent should be able to attain a healthy balance between delightful distractions, and being at peace with their feelings (Barrett \& Gross, 2001; Salovey, et al., 2000). Cooper and Sawaf (2010) stated that although workplace bullying results in deteriorating trust, impaired job performance, jarring 
uncertainty, greater distance between managers and those they manage, dormant creativity, growing cynicism, increasing resentment as well as the disappearance of loyalty and commitment, emotional intelligence can enable employees to enhance reasoning capacities and at the same time make better use of the energy of their emotions, the wisdom of insight and the power intrinsic to the capacity to connect to their core values and beliefs and those around them, that they supervise or work with while mitigating the adverse effect of workplace bullying (Goleman, 2006; Salami, 2010).

Josman (2006) provided empirical evidence showing positive relationships between EI and two aspects of employee work outcomes - task performance and two forms of organizational citizenship behaviours. Employees with emotional intelligence competencies are believed to be more effective and have higher levels of performance outcomes than their peers who lack these strengths (Goleman, 2000). Further, employees with the highest levels of overall emotional intelligence are believed to have the highest overall levels of work performance (Goleman, 2000). Prior research indicates that emotional intelligence competencies under the self-awareness (Selfemotion appraisal) and emotion regulation categories are related to performance (Williams, 2003).

Based on the empirical evidence and assumptions, the present study builds an argument regarding workplace bullying, i.e., that those who fall prey to it lack the emotional intelligence (EI) to deal with the bully. Given that emotions play an important role in performance (Wagner \& Ilies, 2008), it may be reasoned that individuals with high EI will not experience much stress or threat when faced with a perpetrator, and will control their performance at work by regulating their emotions positively and not allowing bullying behaviour to influence their job performance, at least not in the short run. Given that bullying creates negative emotions such as mood changes, feelings of insecurity, anxiety, anger and even guilt (Ayoko et al., 2003; Namie \& Namie, 2009). In the target, the present study posits that targets who are short on emotional intelligence, are more predisposed to such negative emotions. By contrast, those high on emotional intelligence are less likely to suffer adverse emotions. Thus, for those with high EI, detrimental effects on job performance due to bullying experienced at work are less likely, while these effects may be anticipated among those low on EI. Moreover, it is probable that the psychological damage caused by bullying (Fineman, 2004; Giorgi, 2010) can be remedied through 
appropriate emotional management, since emotionally intelligent individuals are adept at psychologically adjusting to adverse events (Berrocal et al., 2006). Similarly, it may be argued that the ability to repair oneself emotionally helps to overcome disturbing, stressful thoughts (Salovey et al., 1995) evoked by bullying behaviour. It is this effective use of emotions that may conceivably moderate the damaging impact of bullying on work performance. Consequently, the impact of bullying on job performance will be less for those high on EI than for those low on EI. In sum, the framework of the present study posits that emotionally intelligent persons are better able to cope with bullying, and thus weaken its negative consequences on their job performance.

Thus it can be hypothesized that:

H4: Emotional Intelligence moderates the relationship between Workplace Bullying and an Individual's Work Performance, such that bullying behaviour has a lower impact on Work Performance for those high on Emotional Intelligence and a higher impact on Work Performance for those who are low on Emotional Intelligence.

Based on the literature a conceptual framework is designed to understand the relationship between workplace bullying, and an individual's work performance and the effect of emotional intelligence on that relationship. The above mentioned relationships are graphically delineated in Figure 1.

\section{Figure 1: Conceptual Framework}

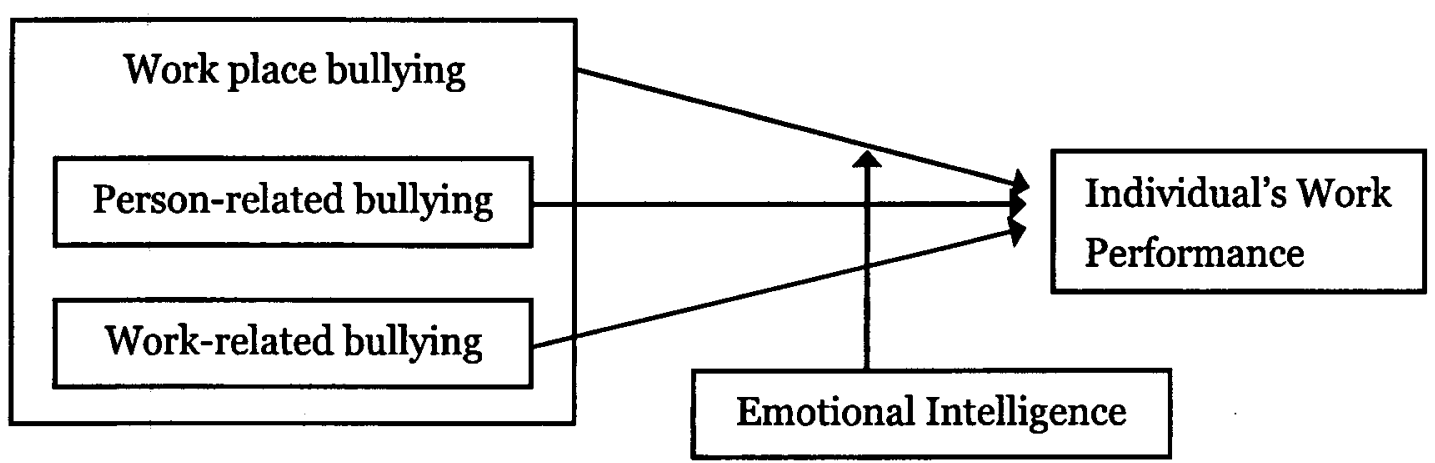


Sri Lankan Journal of Management

Vol. 21, No. 1, January - June, 2016

\section{Methodology}

\section{Participants and Procedure}

This study lies in the pure positivistic research domain. Considering the present study it is not possible to draw a clear idea about the size of the population or the sampling frame, due to the unavailability of a complete listing of managerial level designated employees in the FMCG sector organizations in Sri Lanka. The researcher selected FMCG sector managerial level employees because several studies (Einarsen \& Skogstad, 1996) indicate that with regard to bullying, the health sector and the educational sectors are low-risk sectors, while high-risk organizational settings appear to be large, male-dominated manufacturing companies, multinational organizations where profit is the main motive (Einarsen \& Raknes, 1997; Leymann \& Tallgren, 1989). Out of the total population, a sample of 300 managerial employees was selected to gather primary data. The unit of analysis of the study was the individual as the problem statement was focused on identifying the interests of employees in the organization (Sekaran, 2010). Hence, the unit of analysis of the study is the managerial level employee in the FMCG industry. A convenience sampling technique was adopted. Data was collected through a well-developed and structured questionnaire. Accordingly, a cross- sectional study was conducted (Sekaran \& Bougie, 2010).

\section{Measures}

\section{Workplace bullying}

Workplace bullying was measured using a 22-item scale known as the Negative Acts Questionnaire-Revised (NAQ-R) (Einersen et al., 2009). The NAQ-R is a measure of self reported workplace bullying experiences and examines how often during the last six months respondents have been subjected to a range of negative acts including behaviours such as intimidation, negative or destructive criticism, aggressive and hostile behaviours, and humiliation (Einarsen et al., 2009). All the items are compiled without the actual word "bullying". It is an advantage to let the respondents answer each item without having a perception of bullying before answering (Einarsen et al., 2009). There were 13 items to measure person-related bullying and 9 items to measure work-related bullying. Sample items for work-related bullying are: 'someone withholds information which affects your performance', 'spreading of gossip and rumours about you', 'being exposed to an unmanageable workload'. Sample items 
for person-related bullying are: 'being ignored or facing a hostile reaction when you approach', 'Persistent criticism of your work and effort', 'A five-point Likert scale anchored at $1=$ Never and $5=$ Daily was used. This questionnaire has been used in several studies. These studies were done by Cooper, Faragher and Hoel (2009) (Cronbach's alpha was .91) and Einarsen, Nielsen and Notelaers (2010) (Cronbach's alpha was .89).

\section{Individual's Work Performance}

The individual's work performance was measured using a supervisory rating scale developed by Martin and Shore (1989). Unit head/Immediate manager/ Supervisor provided ratings for each of their subordinates on four scales: dependability, planning, know-how and cooperation with others. Five statements were given to measure each indicator: E.g. statements of planning were, $1=$ 'Even on daily routine work, does not select the most important things to do first and makes poor use of time and resources in getting the job done', $2=$ 'Sometimes selects the most important thing to do first and makes somewhat satisfactory use of time and resources to get the job done', $3=$ 'Usually can select the most important job to do first and makes adequate use of time and resources to get the job done', 4= 'When not overloaded with work can select the most important job to do first and makes good use of time and resources to get the job done', $5=$ 'Even when overloaded with work can select the most important job to do first and makes the best use of time and resources to get the job done'. Supervisors were asked to select only one statement which best describes the performance of the subordinate they evaluate. This evaluation is more accurate than the self-report method and also appropriate in alleviating common method bias. This questionnaire has been used by several researchers for their studies, namely, Bernaards, Hildebrandt (2011) (Cronbach's alpha was .96) and Koopman (2012) (Cronbach's alpha was .92).

Emotional intelligence was measured by using a 16-item scale developed by Wong and Law (2007). Wong's Emotional Intelligence Scale was designed as a contracted measure of EI to be used in organizational research (Wong et al., 2007). This EI scale is based on Davies et al.'s (1998) four dimensional definition of EI and the WLEIS is specially developed for the Asian context. The WLEIS consists of 16 items with each subscale measured with 4 items. The Self Emotion Appraisal dimension assesses individuals' ability to understand and express their own emotions. A sample item is, "I really understand what I feel." The Others' Emotion Appraisal dimension measures 
Sri Lankan Journal of Management

Vol. 21, No. 1, January - June, 2016

peoples' ability to perceive and understand the emotions of others. A sample item is, "I always know my friends' emotions from their behavior." The Use of Emotion dimension denotes individuals' ability to use their emotions effectively by directing them toward constructive activities and personal performance. A sample item is, "I always tell myself I am a competent person." The Regulation of Emotion dimension refers to individuals' ability to manage their own emotions. A sample item of this dimension is, "I have good control of my own emotions." The WLEIS is measured with a five-point Likert scale anchored at $1=$ strongly disagree and $5=$ strongly agree. Similar studies were done by Shih and Susanto (2009) (Cronbach's alpha was .84) and Abedallah and Cohen (2014) (Cronbach's alpha was .92).

\section{Data Analysis and Results}

In order to carry out the data analysis of the study, 300 questionnaires were distributed and 251 usable responses were collected, yielding a response rate of $83 \%$. The collected data were preliminarily scanned for accuracy and precision. Then, they were subjected to a cleaning process. The purpose was to identify outliers and provide treatment for missing values. The data analysis was initiated by entering data into the IBM Statistical package for social sciences (SPSS) software version 20.0. Several plot diagrams/graphs helped in identifying the outliers. Outliers are cases that have out-of-range values, when compared to the majority of other cases. Their presence in the data may distort statistical test results (Malhotra \& Dash, 2011). Outliers are detectable via analysis of the residual scatter plot. Twenty one outliers were deleted and thus only two hundred and thirty questionnaires were used for the final analysis. Since there were no missing values in the data set the researcher proceeded with the rest of the data analysis. A pilot study was done primarily in order to assess the extent of reliability and validity of a research questionnaire. In order to examine face validity, the current questionnaire was reviewed by three industrial experts (senior managerial level employees) to ensure that jargon and technical terms would be understood by the respondents and that they were unambiguous. The questionnaire has also been reviewed by the supervisor of the research study and two senior academics to ensure that the research items (questions) appear to do what they claim to do (Sekaran, 2010). In order to ensure reliability, Cronbach's coefficient alpha (Cronbach, 1946) was used.

Data screening and preliminary descriptive analysis were conducted using SPSS (version 22.0). Preliminary descriptive analysis was carried out. Multivariate 
assumptions were checked prior to inferential statistics. Unidimensionality, reliability and validity of the scales were assured. The sample consisted of one hundred and eleven (48\%) males and one hundred and nineteen (51\%) females. Twenty one ( $9 \%$ ), respondents belonged to the operational level of management, one hundred and fourteen (50\%) respondents belonged to the middle level of management and ninety six (41\%) respondents belonged to the upper middle level of management.

Preliminary descriptive analysis was carried out using statistical techniques such as measurers of central tendency, mean, mode, median and measures of dispersion. Common method variance and non-response bias was also checked before hypothesis testing. Several multivariate assumptions such as normality, multicollinearity and homoscedasticity were assessed prior to hypothesis testing. CFA and SEM were carried out using AMOS (version 22.0; Arbuckle \& Wothke, 2009). The current study adopted $\mathrm{Hu}$ and Bentler's (1998) recommended two-index presentation strategy for the reporting of goodness-of-fit statistics. Specifically, the following fit indices - standardised root mean square residual (SRMR), goodness-of-fit index (GFI), Tucker-Lewis index (TLI), comparative fit index (CFI), parsimony comparative fit index (PCFI), root mean square error of approximation (RMSEA) and the chi-square statistic were used in the data analysis to assess the adequacy of the measurement and the structural models, as well as to report any misspecifications or violations of the assumptions of CFA and SEM. Values for the GFI, TLI, CFI and PCFI were between 0 and 1 , with values closer to 1 representing a better-fitting model. Additionally, a value of .05 or less for SRMR and a value of .08 or less for RMSEA were indicative of good fit. Exploratory Factor Analysis (EFA) was performed to determine the unidimensionality of measures. EFA was performed using principal component analysis and Varimax rotation methods with Kaiser normalization (Kinnear \& Gray, 1997). All items reported above 0.7 level factor loadings. Therefore, the unidimensionality of the variable is satisfactorily ensured. Cronbach's alpha was performed to ensure the purification of the scale. In order to maintain convergent validity, CFA was performed by using structural equation modeling (SEM).

\section{Measurement model}

The measurement model focuses on establishing the validity and reliability of the measures used to represent each construct of the measurement model. Confirmatory Factor Analysis (CFA) with the structural equation model (SEM) was performed using AMOS 20.0 software with the 230 samples. The whole measurement model 
Sri Lankan Journal of Management

Vol. 21, No. 1, January - June, 2016

was developed based on first order confirmatory factor analysis results for each construct. To validate scales in this study, factor scores, average variance extracted (AVE), composite reliability (CR) and squared multiple correlation vs. AVE were calculated. The results of the descriptive statistics, reliability and validity testing are given in the Table 1.

Table 1: Descriptive statistics, Cronbach's alpha, AVE, CR

\begin{tabular}{lccccc}
\hline Variable & Mean & $\begin{array}{c}\text { Standard } \\
\text { Deviation }\end{array}$ & $\begin{array}{c}\text { Cronbach's } \\
\text { Alpha }\end{array}$ & CR & AVE \\
\hline Workplace Bullying & 3.190 & 0.369 & 0.918 & 0.734 & 0.572 \\
Person-related bullying & 2.689 & 0.148 & 0.973 & 0.701 & 0.561 \\
Work-related bullying & 3.913 & 0.267 & 0.817 & 0.711 & 0.548 \\
Emotional Intelligence & 4.481 & 0.983 & 0.928 & 0.865 & 0.631 \\
Individual's Work & 3.519 & 0.278 & 0.937 & 0.719 & 0.523 \\
Performance & & & & & \\
\hline
\end{tabular}

Source: Survey data

Where Goodness of Fit (GOF) indices of the measurement model are concerned, they confirmed the appropriateness of the model. It is generally recommended that multiple indices should be considered simultaneously when overall model fit is evaluated. According to the findings, absolute fit indices (GFI $=0.931, \mathrm{AGFI}=0.964$ and $R M R=0.011$ ) validate the fit between the observed data and the model. Also the incremental indices are above the 0.9 level ( $I F I=0.993, \mathrm{TLI}=0.998$ and $\mathrm{CFI}=0.991$ ) which confirms that the construct fits with the baseline model which assumes that all observed variables are uncorrelated (Hair et al., 2011; p.749).

\section{Structural model}

The purpose of the structural model is to draw conclusions from the sample such as causal relationships and predictions. Figure 2 represents the structural model of the research problem under consideration. The single arrowhead denotes the corresponding direct effect, whereas the statistical estimates of direct effects are given by the path coefficients. 
Figure 2: Structural model with standardized parameter estimates

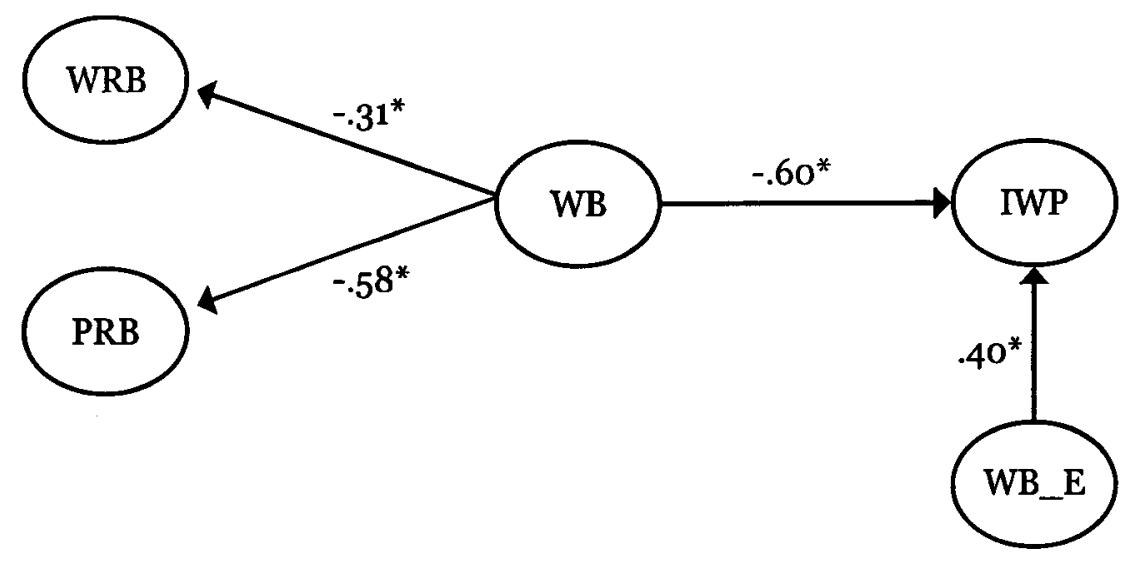

Source: Constructed based on survey data

The structural equation modeling results revealed that the proposed model has an acceptable fit. RMSEA recorded a value of 0.028 indicating a reasonable error of approximation (Brown \& Cudeck, 1993). Absolute fit indices (GFI= 0.931 and $\mathrm{RMR}=0.017)$ and incremental fit indices $(\mathrm{IFI}=0.947, \mathrm{TLI}=0.941$ and $\mathrm{CFI}=0.947)$ indicated a good model fit. According to the path coefficients of the structural model there is a negative relationship between workplace bullying and an individual's work performance $(\beta=-0.60, p<0.000)$. The relationship is significant at the $5 \%$ confidence level. Thus the observed data supported the basic hypothetical relationship.

Aligned with the research objective which was to find the most influential factors for bullying regression weights were compared. The higher regression weight was reported from the impact of person-related bullying on an individual's work performance ( $\beta=-0.58, p<0.000$ ) when compared to the impact of work-related bullying on an individual's work performance $(\beta=-0.31, p<0.000)$. This result indicated that person-related bullying is the most influential form of workplace bullying that impacts on an individual's work performance.

Themoderating effect of emotionalintelligence on the relationship between workplace bullying and an individual's work performance was also tested. An interaction term created as a product of standardised variables (Aiken \& West, 1991) of workplace bullying and EI (WB_EI) was added to examine the potential moderating effect of EI on workplace bullying and job performance. The path from the moderating variable to the endogenous variable is significant $(\mathrm{p}<.05)$ and the impact is positive 
( $\beta=-.40 ; S . E=0.041 ; C R=2.898$ ). In order to test the strength of the moderating effect of EI on workplace bullying and job performance, Baron and Kenny's (1986) procedure and Dawson (2013) and Dawson and Richer's (2006) procedure to test and plot the interaction effect were adopted. The following Figure 3 indicates that work performance is low for those with low levels of emotional intelligence and high for those with high levels of emotional intelligence. In other words, the negative relationship between workplace bullying and work performance is weaker for those who are high on EI and stronger for those with low EI.

Figure 3: Graphical representation of the strength of the moderation

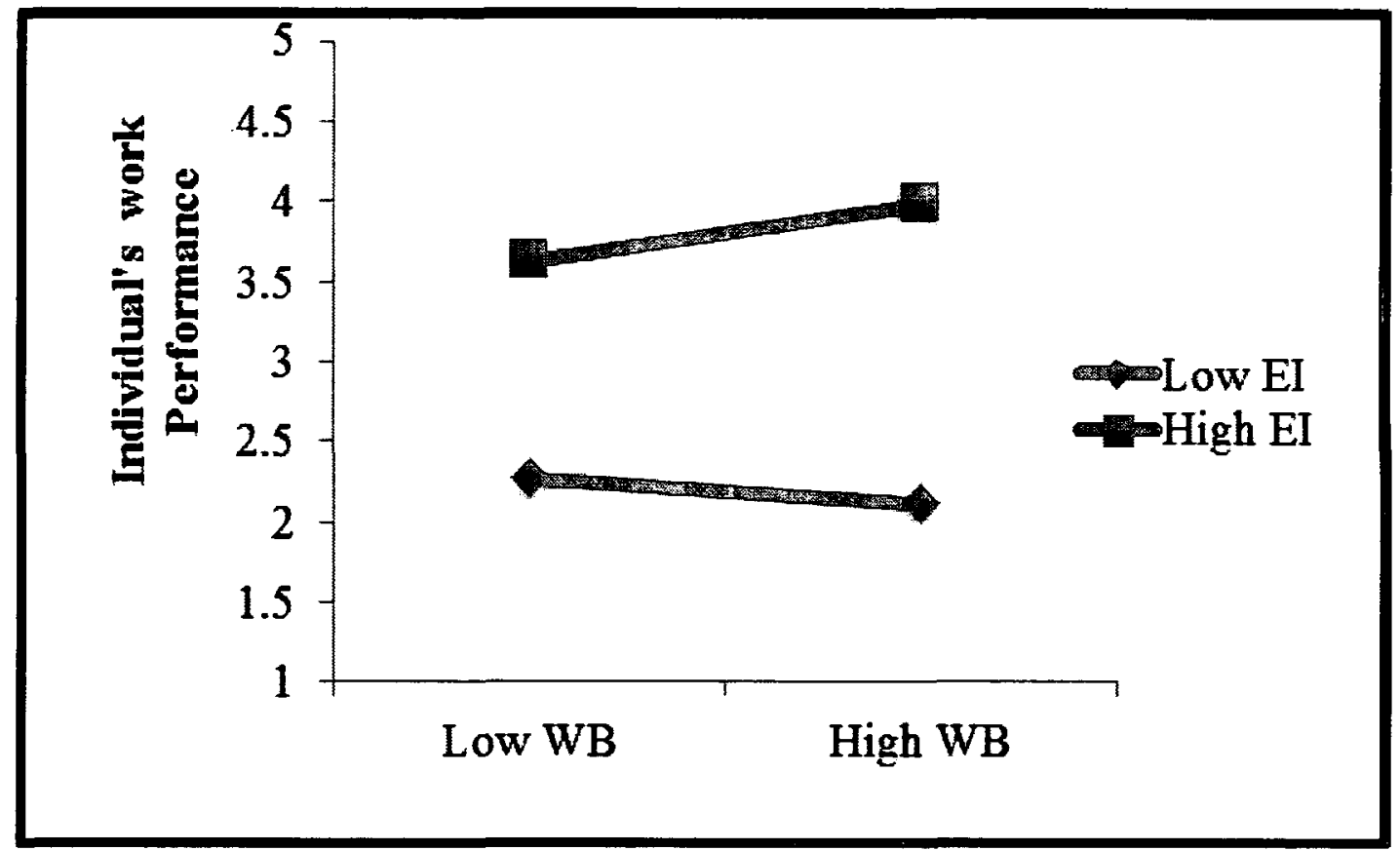

Source: Survey data

\section{Discussion of Findings}

This research focused on examining the impact of emotional intelligence on the relationship between workplace bullying and an individual's work performance. According to the findings of the current study, there is a negative relationship between workplace bullying and an individual's work performance. The direction (negative) which emerges from the current study provides adequate theoretical rationale to the theoretical framework of diverse individual-level consequences of workplace bullying developed by Nielsen and Einarsen (2012). In particular, their model posits that exposure to workplace bullying is likely to influence job-related outcomes and 
health-related outcomes. Their study found that exposure to bullying was associated with increased burnout, reduced job satisfaction and poor task performance. The findings of the current study also support the theoretical argument which points out that greater exposure to bullying was associated with impaired job performance (Jackson et al., 2002; McMillan, 2005). That study has shown that bullying in the workplace impairs the psychological and physical health of its victims, and negatively affects the well-being and efficiency of employees, since negative effects and physical symptoms hold back an employee from performing at an optimal level.

The study confirmed that the relationship between person-related bullying and an individual's work performance and work-related bullying and an individual's work performance is negative. Person related bullying was found to be the dominant form of bullying $(\beta=-0.58)$. Brotheridge and Lee (2010) found person-focused attacks such as public humiliation and undermining self-identity can have a severe impact on work performance. This is in line with the findings of the current study as well. The study of Miles et al., (2007) confirmed the findings of the present study by stating that person- related bullying is a strong contributor towards work performance, and negative acts such as belittling comments and persistent criticism of work appear to inflict harm to employees. The negative relationship between person-related bullying and an individual's work performance which is revealed in the current study strengthens the argument that person-related bullying acts lead to sabotage of performance (Margeret, 2007). The findings of the current study are clearly congruent with the arguments of Yahaya et al., (2009). According to their study, person-related bullying causes a lack of focus on work tasks and a loss of self-confidence on the job, and it is regarded as a form of stress capable of causing negative effects on workers' health, potentially leading to impaired job performance.

The findings of the current study strengthens the argument of Beswick et al., (2006) that work-related bullying behaviours such as assigning unachievable tasks, impossible deadlines, unmanageable workloads, meaningless tasks or supplying unclear information lower the performance level of employees. The negative relationship between work-related bullying and individual work performance is confirmed by the findings of Brotheridge and Lee (2010). According to them, workrelated bullying-induced emotions might have a negative impact on the target's job performance. 


\section{Sri Lankan Journal of Management}

Vol. 21, No. 1, January - June, 2016

The moderating impact of emotional intelligence on the relationship between workplace bullying and an individual's work performance is in line with the findings of Aldea and Rice (2006), which outline that individuals' ability to effectively confront and cope with a problem depends upon their ability to regulate their emotions. According to them, greater emotional intelligence is associated with higher levels of effective problem-solving, such as allowing individuals to create a multitude of problem-solving perspectives. The findings of the current study is authenticated by the argument of Matthews and Ziender (2005) which posits that individuals' emotional intelligence skills influence their choice of coping strategies to deal with the stressful situations they face. Chan (2006) also found that individuals with enhanced emotional intelligence are less vulnerable to work-related stress generated by workplace bullying and harrasment. Additionally, emotional intelligence results in a healthy balance between distractions and being at peace with one's feelings (Barrett \& Gross, 2001; Salovey, et al., 2000). Cooper and Sawaf (2010) stated that workplace bullying results in deteriorating trust, impaired job performance, jarring uncertainty, greater distance between managers and those they manage, dormant creativity, growing cynicism, increasing resentment as well as the disappearance of loyalty and commitment conversely, emotional intelligence can enable employees to enhance reasoning capacities and at the same time make better use of their emotions, of the wisdom of insight and the power intrinsic to their capacity to connect with core values and beliefs in themselves and those around them, so that they can supervise or work with others while mitigating the adverse effects of workplace bullying (Goleman, 2006; Salami, 2010). Therefore, it can be concluded that emotional intelligence plays a very important role in enhancing both organizational and individual performance.

\section{Theoretical Contribution}

Emerging research interest in the relationship between workplace bullying and an individual's work performance, resulted in research that looked at the notion in various contexts and found that workplace bullying leads to the deterioration of an individual's work performance. Even though there is much discussion in the literature on the importance of emotional intelligence in mitigating the negative effects of workplace bullying, there is a marked lack of empirical evidence to support this postulation. Hence, this study, which examined the ability of emotional intelligence to alleviate the impact of workplace bullying on an individual's work performance, addresses this lacuna by providing empirical support for the long-held belief about 
the impact of emotional intelligence on the phenomenon of workplace bullying and the individual's work performance.

The findings of the current study suggest that individualized transactional coping theory can be a useful conceptual framework in explaining the use of emotional intelligence to alleviate the impact of workplace bullying on an individual's work performance. According to individualized transactional coping theory when people encounter stressful life events, they look for ways to change the adverse effects of these events on their well-being by using a number of coping strategies (Akgun, 2004). Emotional regulation and self-emotion appraisal are identified as coping strategies which are used to cope with stressful situations such as workplace harassment, workplace bullying and abusive supervision (Lazarus, 1999). Emotional regulation and self-emotion appraisal are major components of emotional intelligence. Therefore, the findings of the current study validate the theoretical underpinning of individualized transactional coping theory by empirically validating the aforementioned coping strategies in the context of workplace bullying and an individual's work performance. The findings of the current study advance the existing literature on coping by empirically validating emotional intelligence as a coping mechanism that overcomes the stress generated by bullying incidents.

The current research findings contribute to the current debate about the effects of workplace bullying on work performance, by adopting the attribution theory which outlines that the reaction towards negative incidents varies according to the attribution process of the individual. Further, bullying often results in subjective interpretations of the behaviour; therefore the impact of the negative incident varies according to the way the target interprets the negative motive or the intent of the incident. Hence, the findings of the present study challenges the long held conceptualization that workplace bullying leads to an impaired work performance. It establishes a new direction that the reaction towards stressful life events such as workplace bullying is subjective and can paradoxically result in positive effects on the target's performance when the target does not interpret the incident in a negative manner.

\section{Managerial Implications}

A major contribution of this study is that it emphasizes the importance of emotional intelligence specifically in alleviating the negative consequences of workplace bullying. 


\section{Sri Lankan Journal of Management}

Vol. 21, No. 1, January - June, 2016

It is important for practitioners to understand the current debate surrounding the topic and the potential positive implications of a successful integration of EI at work. It is also important to popularize the notion that while EI may indeed be an individual characteristic, it can be developed over time and can be improved and harnessed through proper training and development initiatives (Ashkanasy \& Daus, 2005). Therefore, EI should be a major focus in training and development efforts at all organizational levels. Development of emotional intelligence in managers dealing with the demands, rapidity and uncertainty of change may help them become aware of their own needs and the needs of others. With the training of emotional intelligence, managers can conduct themselves in a way that does not affect the health or wellbeing of other organisational members. It can further assist managers to learn to deal with their emotions in more appropriate ways than resorting to bullying behaviours, and to be more attuned to the feelings of others. EI training should be able to ensure that all employees are equipped with effective strategies for managing their feelings, expressing even negative emotions in an appropriate way, and behaving empathetically. Based on the findings it can be suggested that emotional intelligence should be established as a criterion when hiring a candidate for a managerial position. If employees are emotionally healthy and strong they are capable of handling stressful situations which are common in the corporate sector and specifically in the multinational arena, and they will not exhibit deviant behaviors such as workplace bullying techniques to extract work from colleagues and subordinates.

Person-related bullying is found to be the most influential form of bullying in the corporate sector in Sri Lanka. Employees who engage in person-related bullying activities are a tremendous cost to the organization. HR practitioners should be able to identify those who engage in person-related bullying activities (perpetrators) and direct them for counseling and special emotional intelligence programmes which would be beneficial to the organization, its employees and perpetrators. Further, attention must also be paid to victims of person-related bullying and HR should direct them for counseling programs if necessary. As discussed above, due to intense competition in the industry, managers are sometimes compelled to deploy bullying techniques to get the maximum output from their subordinates. Particularly work-related bullying techniques may be deployed involuntarily. To avoid this HR practitioners in multinational organizations should formulate intervention strategies including emotional intelligence competencies where both individual and organization are benefited. Workplace bullying is destructive in the emotional sense 
to the individual, and in the financial sense to the organisation (Carbo \& Hughes, 2010; Boddy, 2011). Organisations aiming at improved performance must take into account the health and emotional aspects of their members. As prevention is better than cure, circumstances that lead to bullying can be avoided in a proactive manner if organizations can prioritize emotional intelligence as an intervention strategy when dealing with workplace bullying, and thus enhancing performance.

EI should also become a relevant criterion when it comes to promotions and succession planning, particularly when a position involves leadership. By making emotional intelligence a priority, the implementation of human resource functions will allow organizations to show that they mean what they say when referring to employees as their most important asset. When there is zero tolerance for workplace bullying, and there is a commitment to provide an environment that encourages, supports and reinforces the self-directed development process of emotional intelligence competencies, bullying can be reduced. Human resource professionals can conduct periodic emotional intelligence evaluations for employees. These evaluations help to reveal how employees perceive themselves and each other and how they react to difficult situations and emotions. This understanding helps to maintain a conducive organizational culture which enhances an individual's work performance and reduces deviant behaviours such as workplace bullying. Moreover human resource practitioners can also take necessary steps to integrate EI into performance management systems. Integration of Emotional Intelligence into reviews, planning processes and other methods that measure the performance of employees can help to ensure that EI becomes a regular practice, rather than a oneoff activity and being clear about the behaviours that are expected for each capability provides more role clarity for employees.

According to the findings of the study it can be stated that predominantly personrelated bullying and secondly, work-related bullying prevail in the corporate sector (FMCG) in the Sri Lankan context. This can be considered an warning to all related parties to take precautionary measures to mitigate such activities and to ensure a healthy organizational environment for all employees. In this regard, it is necessary to reassert the need for leadership in order to create an anti-bullying climate based on trust and integrity in organizations (Stogstad et al., 2011). An anti-bullying climate will lead to lower stress and anxiety levels among employees, higher commitment, reduced turnover, better employee health and consequently better job performance. Moreover, organisations may introduce anti-bullying policies and intervention 


\section{Sri Lankan Journal of Management}

Vol. 21, No. 1, January - June, 2016

strategies to encourage an anti-bullying climate (Sheehan, 1999). Earlier studies (Overall, 1995) have suggested firm measures, such as legal recourse, to minimize bullying. Such remedial actions would ensure the emotional and physical health of employees; healthier, happier employees working in a bullying-free environment are expected to be more productive, and their contribution to enhanced organisational performance would be an added benefit. Person-related bullying is found to be the dominant form of workplace bullying which affects an individual's work performance. Structural changes and procedural revisions also would provide necessary assistance to create an anti-bullying environment. It is imperative for organizations to take remedial action to protect employees from the mental strain which can occur due to person-related bullying, and also ensure a bullying-free organizational ambiance in which to conduct work activities effectively and efficiently.

\section{Limitations and Future Research}

There are several limitations to this study, which require further examination and additional research. Firstly in this research the independent variable, dependent variable and moderating variables were measured at the individual level. However, as bullying behaviour may be directed either towards an individual or a group, (Kisamore, 2010) it is suggested that a group-level analysis be performed in future. Such a study would likely provide worthwhile findings for teams and groups in organisations. Since this study has been based on managerial level employees of the corporate sector, as discussed above, with regard to workplace bullying, high risk sectors are male dominated industries, blue-chip organizations and manufacturing firms and low risk sectors are the health sector, and the education sector. Therefore, the generalisability of findings is limited, and a different sample from another industry such as education, engineering or telecommunications might have yielded different results.

Moreover, future research should examine gender differences with regard to emotional responses within the studied relationship for a more holistic framework and for theory-building. As this research has proven that workplace bullying negatively impacts job performance, a similar adverse effect is likely to affect other aspects of the work environment, such as turnover intentions, employee stress, workplace conflict, workplace climate and so on. Finally, it can be expected that targets of bullying behaviour may develop certain personality traits such as neurosis, 
and may become prone to prone anxiety, nervousness and depression. Future research could examine these issues in depth.

\section{Conclusion}

This study shows that the effect of workplace bullying on an individual's work performance is subjective, and differs according to the emotional intelligence state of the individual. Therefore, individuals who have higher levels of emotional intelligence are capable of mitigating the adverse effects generated by workplace bullying on their well-being, and perform their duties without being very much affected by the bullying activities. Since emotionally intelligent individuals are adept at psychologically adjusting to adverse events, the detrimental effects on their job performance due to bullying experienced at work are relatively less.

\section{References}

Agervold, M., \& Mikkelsen, E. G. (2004). Relationships between bullying, psychosocial work environment and individual stress reactions. Journal of Work and Stress, 18(4), 336-351.

Aiken, L.S., \& West, S.G. (1991). Multiple Regression: Testing and Interpreting Interactions, Newbury Park, CA: Sage

Akgun, S. (2004).The effects of situation and learned resourcefulness on coping responses. International Review of Industrial and Organizational Psychology 21(2), 1-34.

Aldea, N.M., \& Rice, C.S. (2006). Emotion in the workplace: the new challenge for managers. Academy of Management Executive, 16(1), 76-86.

Abedallah, N., Cohen, H. (2014). Emotional intelligence in organizations. In C. L. Cooper \& I. T. Robertson (Eds.), Chichester: Wiley.

Anshel, A.F. (2001). Beyond Baron and Kenny: statistical mediation analysis in the new era. Journal of the Statistics, 31(3), 323-326.

Aquino, K. (2008). Structural and individual determinants of workplace victimization: The effects of hierarchical status and conflict management style. Journal of Management, 26, $57-68$

Arbuckle, J. L., \& Wothke. (2009). AMOS (Version 7) [Computer software]. Chicago: SPSS.p.26 


\section{Sri Lankan Journal of Management}

Vol. 21, No. 1, January - June, 2016

Ashkanasy, A., \& Daus, T. (2005). The relationship between emotional intelligence and work attitudes, behavior and outcomes: An examination among senior managers. Journal of Managerial Psychology, 18(8), 788-813.

Auerbach, G., \& Gramling, S. (1998). Coping with occupational problems: the limits of individual efforts. Journal of Health and Social Behaviour, 25, 406-423. doi: 2307/2136379.

Ayoko, O.B., Callan, V.J., \& Hartel, C.E. (2003). Workplace conflict, bullying and counterproductive behaviours. International Journal of Organisational Analysis 11(4), 283-301.

Baron, M. R., \& Kenny, A. D. (1986). The Moderator-Mediator Variable Distinction in Social Psychological Research: Conceptual, Strategic, and Statistical Considerations. Journal of Personality and Social Psychology, 51(6), 1173-1182.

Barret, R., \& Gross, A. (2001). Influence of teacher empowerment on teachers organizational commitment, professional commitment and organizational citizenship behavior in schools. Teaching and Teacher Education, 20(3), 277-289.

Bernaards, B., \& Hildebrandt, C. (2011). Inside the Workplace: Findings from the 2004 Workplace Employment Relations Survey. London: Routledge.

Berrocal, R. A., Jette, R. D., \& Katzell, R. A. (2006). The effects of psychologically based intervention programs on worker productivity: A meta-analysis. Personnel Psychology, $38,275^{-291}$.

Beswick, E., Gore, J., \& Palferman, T. (2006). Experiences of belittlement and harassment and their correlates among medical students in the United States: Longitudinal survey. British Medical Journal ,333(7), 682-688.

Björkqvist, W., Österman, J., \& Hjelt-Bäck.,K. (2011). Aggression among university employees. Aggressive Behavior, 20, 173-184.

Baxter, R., \& Blaithwhite, R. P. (2008). On the Nature and Direction of Relationships between Constructs and Measures, Journal of Research Methods, 5(2), 155-174.

Borman, W. C., \& Motowidlo, S. J. (2000). Task performance and contextual performance: The meaning for personnel selection research. Journal of Human Performance, 10, 99109.

Bowling, N. A., \& Beehr, T. A. (2006). Workplace harassment from the victim's perspective: A theoretical model and meta analysis. Journal of Applied Psychology, 91(5), 998-1012.

Brown, M.W., \& Cudeck, R. (1993). Alternative ways of assessing model fit. Journal of Statistics, 18(4), 42-56.

Brotheridge, E.K. \& Lee, J.M. (2010), The social stressors-counterproductive work behaviors link: are conflicts with supervisors and coworkers the same. Journal of Occupational Health Psychology, 11(2), 145-156. 


\section{The Role of Emotional Intelligence on Workplace Bullying and Individuals' Work Performance}

Cartwright, J. (2008), Relations between social and emotional competence and mental health: a construct validation study. Personality and Individual Differences, 35, 1947-1963.

Cascio., R.S. (2005), A meta-analysis of the relationship between organizational citizenship behavior and counterproductive work behavior. Journal of Applied Psychology, 90 (6), 430-441.

Cassitto, M. G., Cowie, H., Naylor, P., Rivers, I., Smith, P. K., \& Pereira, B. (2004). Measuring workplace bullying. Aggressive Violent Behaviour, 7, 35- 51.

Cavanaugh, C. S., Wiprzycka, U., Hasher, L., \& Goldstein, D. (2000). Seeing the glass half full: Optimistic expressivewritingimprovesmental healthamong chronicallystressed caregivers. British Journal of Health Psychology, 13, 73-76, doi: 10.1348/135910707X251153

Chan, D.W. (2006). Emotional intelligence and components of burnout among Chinese secondary school teachers in Hong Kong. Journal of Teaching and Teacher Education, 22(8), 1042-1054

Charlesworth, K. (2006). Perceptions and experience of workplace bullying in five different working populations. Aggressive Behaviour, 29, 489-496.

Coetzee, M., Martins, N., Basson, J.S., \& Muller, H. (2006). The relationship between personality preferences, self-esteem and emotional competence. SA Journal of Industrial Psychology, 32(2), 64-73.

Cooper, I. \& Sawaf, I. (2010). Emotional intelligence in the workplace: exploring its effects on occupational stress and organizational commitment. The International Journal of Organizational Analysis, 10(4), 327-342.

Cooper, M.N., Faragher, S.N., \& Hoel,H .(2009). Benefits of multiple roles for managerial women. Academy of Management Journal, 45 (2), 369-386.

Coyne, I., Chong, P.S., Seigne, E., \& Randall, P. (2004). Self and peer nominations of bullying: an analysis of incident rates, individual differences, and perceptions of the working environment. European Journal of Work and Organizational Psychology, 12, 209-228.

Crawford, N. (1998). Conundrums and confusion in organisations: the etymology of the word bully". International Journal of Manpower, 20, 86-93.

Cronbach, L. J. (1946). Response sets and test validity. Educational and Psychological Measurement, 6(4), 475-494.

Cronbach, L., 1990. Essentials of psychological testing. Harper \& Row, New York.

Dawson, J.F., \& Richer, N.G. (2006). Potential Problems With Well Fitting' Models, Journal of Abnormal Psychology, 112(4), 578-598.

Dawson.J.F. (2013). Moderation in Management Research why,when and how. Journal of Business and Psychology, (29), 1-19. 


\section{Sri Lankan Journal of Management}

Vol. 21, No. 1, January - June, 2016

Djurkovic, N., McCormack, D. \& Casimir, G. (2008). The physical and psychological effects of workplace bullying on intention to leave: a test of the psychosomatic and disability hypotheses. International Journal of Organization Theory and Behavior, 7, 469-497.

Einarsen, S. (2000). Harassment and bullying at work: a review of the Scandinavian approach. Aggression and Violent Behavior, 5 (4), 379-401.

Einarsen, S. (2009). The nature and causes of bullying at work. International Journal of Manpower, 10, 16-27.

Einarsen, S. (2010). Bullying at work. Aggression and Violent Behaviour, 34, 80-96.

Einarsen, S., \& Raknes, B. I. (1997). Harassment in the workplace and the victimization of men. Journal of Violence and Victims, 12(3), 247-263.

Einarsen, S., \& Skogstad, A. (1996). Bullying at work: Epidemiological findings in public and private organizations. European Journal of Work and Organizational Psychology, 5, 185-201.

Einarsen, S., Hoel, H., \& Notelaers, G. (2009). Measuring bullying and harassment at work: Validity, factor structure, and psychometric properties of the Negative Acts Questionnaire - Revised. Work and Stress, 23(1), 24-44.

Einarsen, S., Hoel, H., \& Notelaers, G. (2011). Measuring bullying and harassment at work. Work and Stress, 53(7), 69-80.

Einarsen, S., Hoel, H., Zapf, D. \& Cooper, C.L. (Eds) (2011). Bullying and Harassment in the. International perspectives in research and practice. (pp. 127-144).

Eskay, B. (2011). Racial/ethnic bullying: Exploring links between bullying and racism in the US workplace. Journal of Vocational Behavior, 66, 438-456.

Fineman, F.J. (2004). Some historical and scientific issues related to research on emotional intelligence. Journal of Organizational Behavior, 26(4), 411-424.

Finn, B.L., \& Chattopadhyay, C. (2000). Positive emotions broaden the scope of attention and thought-action repertoires. Cognition and Emotion, 19(3), 313-332.

Folkman, S., \& Moskowitz, S. (2004). An analysis of coping in a middle-aged community sample. Journal of Health and Social Behavior, 21, 219-239. Retrieved from: http://www. jstor.org/stable/

French, N., \& Bell. (2009). Co-worker trust as a social catalyst for constructive employee attitudes. Journal of Managerial Psychology. 19(6), 608-622.

Furnham, F.E. \& House, R.J. (2010). Leadership theory and research: A report of progress. International Review of Industrial and Organisational Psychology, 19(88), 73-91. 
Giorgi, H., \& Majer, W.S. (2008). The relationship between emotional intelligence and job performance in a call centre environment. South African Journal of Industrial Psychology, 3o(3), 75- 81

Giorgi, $\mathrm{H}$ (2010). The relationship between trait emotional intelligence and job performance. South African Journal of Psychology, 4O(3), 532- 541

Goleman, D. (2000). The mediating effect of burnout on the relationship between structural empowerment and organizational citizenship behaviours. Journal of Nursing Management, 18 (3), 339-348.

Goleman, D. (2006). Emotional intelligence: Issues in paradigm building. In C. Cherniss \& D. Goleman (Eds.). The Emotionally Intelligent Workplace (pp.13-26). Jossey-Bass: San Francisco.

Hagihara, A., Rezapur, A., Hashemi, J. \& Mohammadi, I. (2003), "An investigation of the changing nature employees. European Journal of Experimental Biology, 36(4), 235-251.

Hair, J. F., Sarstedt, M., Ringle, C. M., \& Mena, J. A. (2011). An assessment of the use of partial least squares structural equation modeling in marketing research. Journal of the Academy of Marketing Science, 4o(3), 414-433. doi:10.1007/s11747-011-0261-6.

Harvey, S., \& Keashly, L. (2007). Predicting the risk for aggression in the workplace: Risk factors, self-esteem and time at work. Social Behavior and Personality, 31(8), 807-814.

Halal, K.J., (2007). Strategic groups, asymmetrical mobility barriers and contestability. Strategic Management Journal, 8, 329-342.

Hauge, L., Skogstad, A., \& Einarsen, S. (2010). The relative impact of workplace bullying as a social stressor at work. Scandinavian Journal of Psychology, 51 (9), 426-433.

Hilmer, D. A., \& Donaldson, S. J. (2006). Mapping individual performance over time. Journal of Applied Psychology, 77, 185-195.

Hoel, H., \& Cooper, C.L. (2000). Origins of bullying: Theoretical frameworks for explaining bullying. In N.Tehrani (Ed.), Building a Culture of Respect: Managing Bullying at Work (pp. 3-19 London: Taylor \& Francis.

Hoel, H., Cooper, C. L., \& Faragher, B. (2003). The experience of bullying in Great Britain: The impact of organizational status. European Journal of Work and Organizational Psychology, 10, 443-465.

Hoel, H., Rayner, C., \& Cooper, C.L. (2004). Workplace bullying. International Review of Industrial and Organizational Psychology, 14, 195-230.

Jackson, D., Clare, J. \& Mannix, J. (2002). Who would want to be a nurse? Violence in the workplace - a factor in recruitment and retention. Journal of Nursing Management, 1O(1) 13-20. 


\section{Sri Lankan Journal of Management}

Vol. 21, No. 1, January - June, 2016

Josman, P.J. (2006). Linking conflict strategy to the five-factor model: theoretical and empirical foundations. International Journal of Conflict Management, 12 (1), 47-68.

Judith, M. R. (2008). Workplace bullying: The role of psychosocial work environment factors. International Journal of Stress Management, 16(3), 215-232.

Keashly, L., \& Neuman, K. (2004). By another name: American perspectives on workplace bullying. In S. Einarsen, H. Hoel, D. Zapf, \& C. L. Cooper (Eds.), Bullying and emotional abuse in the workplace. International Perspectives in Research and Practice (pp. 31-61). London: Taylor \& Francis.

Kinnear, B., \& Gray, D. (1997). A comparison of some methodologies for the factor analysis of non-normal Likert variables: A note on the size of the model. British Journal of Mathematical and Statistical Psychology, 45, 19-30.

Koopmans,I (2011), Comparative effects of personal and situational influences on job outcomes of new professionals. Journal of Applied Psychology, 72, 558-566.

Koopmans, I (2012) Procedural justice in performance evaluation-the role of instrumental and noninstrumental voice in performance-appraisal discussions. Journal of Management, $21,657-669$.

Kisamore, T. (2010). Organizational legitimacy under conditions of complexity: the case of the multinational enterprise. Academy of Management Review, 24, 64-81.

Lazarus, R.S. \& Folkman, S. (1984). The Concept of Coping. In A. Monat \& Lazarus, R. S. (Eds.) (1991) Stress and Coping: An Anthology. New York: Columbia University Press

Lazarus, R. S. (1999). Stress Appraisal and Coping. Springer, New York, NY.

Leymann, H. (2006). The content and development of mobbing at work. European Journal of Work and Organizational Psychology, 5(2), 165-184.

Leymann, H., Tallgren,G. (1989). Mobbing and bullying at work. Danish Journal of Organizational Psychology, 22(5), 131-154.

Lovell, H., \& Lee, A. (2011). Mobbing at working and the development of post-traumatic stress disorders. European Journal of Work and Organizational Psychology, 5, 251-275.

Leymann, H., \& Gustafsson, A. (1996). The role of trait emotional intelligence in a genderspecific model of organizational variables. Journal of Applied Social Psychology, 36.(2), 20-32

Lutgen, P. N., \& Sandwik, P. (2008). Emotional intelligence and social interaction. Personality and Social Psychology Bulletin, 30, 1018-1034.

Limerick, B.L., \& Cunnigton, R.T. (2003). Impact of workplace bullying on emotional and physical well-being: a longitudinal collective case study. Journal of Aggression, Maltreatment and Trauma, 20 (3), 344-357. 


\section{The Role of Emotional Intelligence on Workplace Bullying and \\ Individuals' Work Performance}

Malhotra, N. K. Dash. S. (2011). Marketing Research An Applied Orientation. Sixth Edition, Delhi, Pearson Prentice Hall, 170-203.

Margaret H. (2007). Case Study of Workplace Bullying. Organization Management Journal $10,139-147$.

Martin, C., \& Shore, M. (1989). Measuring the extent of impact from occupational performance on organizational behaviour. Employee Responsibilities and Rights Journal, 16, 117-134.

Martins, J., Ramalho D.H., \& Morin, R.B. (2010). Positive and negative affective outcomes of occupational stress. New Zealand Journal of Psychology, 35 (2), 590-601.

Matthews, G., Emo, A., Funke, G., Roberts, R., Zeidner, M., Costa, P., \& Schulze, R. (2002). Emotional Intelligence, personality and task-induced stress. Journal of Experimental Psychology, 12, 96 - 107. doi: 10.1037/1076-898X.12.2.96

Matthews, M., \& Ziender, O. (2005). Trait emotional intelligence and the cognitive appraisal of stressful events: an exploratory study. Personality and Individual Differences, 44 (7), 1445-1453.

Mayer, J.D., \& Sullivan, P. (2007). What is emotional intelligence: implications for educators. In Salovey, P. \& Sluyter, D. (Eds), Emotional Development, Emotional Literacy, and Emotional Intelligence. Basic Books, New York, NY, pp. 3-31.

McCarthy, D.C. (1996). Job experience correlates of job performance. Journal of Applied Psychology. 73, 47-56.

McMillan, I. (2005). Losing control. Nursing Times, 91 (15), 40-43.

Mikkelsen, E.G., \& Einarsen, S. (2001). Relationships between exposure to bullying at work and psychological and psychosomatic health complaints: the role of state negative affectivity and generalized self-efficacy. Scandinavian Journal of Psychology, 43, 397-405.

Miles, D. C. \& Shevlin, N. J. (eds) (2007). Handbook of Research Design and Social Measurement (6th ed). Thousand Oaks, CA: Sage.

Miles, E., \& Salin, D. (2007). Prevalence and forms of bullying among business professionals. A comparison of two different strategies for measuring bullying. European Journal of Work and Organizational Psychology, 10(4), 425-441.

Munthe, J. (2009). Workplace bullying: a cross-level assessment. Management Decision, 44(9), 1214-1230.

Namie, G., \& Namie, R. (2009). Prevalence of Workplace bullying: Timely discussion. Ivey Business Journal, 68(2) 101-116.

Nielsen, M. B., \& Einersen, S. (2012). Prevalence of workplacebullying in Norway: Comparisons across time and estimation methods. European Journal of Work and Organizational Psychology, 18 (1), 11-23. 


\section{Sri Lankan Journal of Management}

Vol. 21, No. 1, January - June, 2016

Nielsen, M. B., \& Notelaers, C.L. (2010). Attachment, emotional loneliness, and bullying behavior: a study of adult and young offenders. Aggressive Behavior, 30, 298-312.

O'Moore, A. M., \& Hillery, B. (2008). Bullying in Dublin private sector organizations. Irish Journal of Psychology, 10, 426-441.

Overall, M. (1995). The relationship between interpersonal conflict and workplace bullying. Journal of Managerial Psychology, 30 (3), 250-268.

Pascale, S. K. (2008). That's not my job: Developing flexible employee work orientations. Academy of Management Journal, 40, 899-929.

Rick, A. \& Guppy, Z.E. (1994). The relationship among emotional intelligence, task performance, and organizational citizenship behaviors. Human Performance, 19 (4), 403419.

Riley, J., \& Schutte, V. (2003). Exploring the work/life/study balance: the experience of higher education students in a Scottish further education college. Journal of Further \& Higher Education, 31(3), 225-238.

Salami, S. O. (2010). Conflict resolution strategies and organizational citizenship behavior: The moderating role of trait emotional intelligence. Social Behavior and Personality, 38 (1), 75-86.

Salin, D. (2003). Prevalence and forms of bullying among business professionals. A comparison of two different strategies for measuring bullying. European Journal of Work and Organizational Psychology, 5, 425-442.

Salovey, F., Stroud, J., Woolery, D.M., \& Epel, R.C. (200o), A cross-cultural exploratory study of the linkage between emotional intelligence and managerial effectiveness. International Journal of Organizational Analysis, 11 (3), 171-191.

Salovey, P., Bedell, B.T., Detweiler, J.B., \& Mayer, J.D. (1995). Coping intelligently: Emotional intelligence and the coping process. In C.R. Snyder (Ed.), Coping: The psychology of what works (pp. 141-164). New York: Oxford University Press.

Samnani, A. (2012). 20 years of workplace bullying research: a review of the antecedents and(6),. Consequences of bullying in the workplace. Aggression and Violent Behavior, 17 (6), 581-589 Workplace: Developments in Theory, Research, and Practice, (2nd ed). New York

Samnani, A. K., Singh, P., \& Ezzedeen, S. (2013). Workplace bullying and employee performance: an attributional model. Organizational Psychology Review, 1 (1), 1-23.

Sekaran, U. (2010). Research methods for business: A skill building approach. John Wiley \& Sons.

Sekaran, U., \& Bougie D. (2010). Linking theory to practice: a grand challenge for management research in the 21st century. Organization Management Journal, 1(1), 10-14. 
Seligman, C., \& Csikszentmihalyi, G.P. (2000). The situational interview as a predictor of academic and team performance: A study of the mediating effects of cognitive ability and emotional intelligence. International Journal of Selection and Assessment, 12, 312-320.

Sheehan, C.D. (1999). The structure of psychological wellbeing revisited. Journal of Personality and Social Psychology, 69 (4), 897-915.

Sinclaire, M., Lynch, J., \& Niamh, N. D. (2009). The rates and relative risks of workplace bullying in Ireland, a country of high economic growth. International Journal of Management and Decision Making, 4 (1), 82-95.

Shih, L. J., \& Susanto, R. J. (2009). Recent Advances in emotional intelligence. Journal of Management, 29(6), 903-936.

Skinner, J. D. \& Brewer, C. D. (2002). Educational policy on emotional intelligence: Does it make sense? Educational Psychology Review, 12, 163-183

Slaski, M., \& Cartwright, S. (2002). Health, performance and emotional intelligence: an exploratory study of retail managers. Stress and Health, 18(2), 63-68.

Slaski, M., (2010). Emotional intelligence and performance. Social Behavior and Personality, 69(2), 132-161.

Stainton, P.E., \& Rogers, S. (2011). An emotion-centered model of voluntary work behavior: Some parallels between counterproductive work behavior (CWB) and organizational citizenship. Social Behavior and Personality, 58(12), 111-123.

Stogstad, C., Sheehan, M., \& Rahm, M. (2011). Theoretical approaches to the study of bullying at work. International Journal of Manpower, 2O(1), 11-15.

Viswesvaran, A., \& Ones, D. (2008). Mobbing in the workplace by peers and managers: mobbing experienced by nurses working in healthcare facilities in Turkey and its effect on nurses. Journal of Clinical Nursing, 16(8), 1444-1453.

Visconti,Y., Secler,K \& Kochendefer, U(2013). The sources of bullying - psychological work environment and organizational climate. European Journal of Work and Organizational Psychology, 5, 203-214.

Wagner, B.L. \& Ilies, D.L. (2008). Eustress at work: the relationship between hope and health in hospital nurses. Health Care Management Review, 26 (4), 7-18.

Warr, P. (2006). Differential activation of judgments in employee well-being. Journal of Occupational and Organizational Psychology, 79, 225-244.

Weisinger G. (1998). The impact of social environments on emotional, social, and cognitive competency development. Journal of Management Development, 27 (1), 129-145.

Weiss, M.E., \& Cropanzano, M. (2006). Positive psychology: an introduction. American Psychologist, 55 (1), 5-14. 


\section{Sri Lankan Journal of Management}

Vol. 21, No. 1, January - June, 2016

Williams, J.L., \& Porter, L.W. (2003). Employee responses to formal performance appraisal feedback. Journal of Applied Psychology, 71 (2), 211-8.

Wong, C.S., Law, K.S., \& Wong, P.M. (2007). Development and validation of a forced choice emotional intelligence measure for Chinese respondents in Hong Kong. Asia Pacific Journal of Management, 21, 535-559.

Yahaya, J., Kivimaki, M., Elovainio, M., Virtanen, M., Keltikangas-Jarvinen, L., \& Vahtera, J. (2009). Psychosocial work characteristics and incidence of newly diagnosed depression: a prospective cohort study of three different models. Social Science and Medicine, 61 (1), 111-122. 